\title{
Trends in Mycology: An overview of the one day meeting, Braga, Portugal, 23rd September 2005
}

\author{
R. Russell M. Paterson \& Nelson Lima \\ Centro de Engenharia Biológica, Micoteca da Universidade do Minho, Braga, Portugal
}

This meeting was born from the idea of inviting David Hawksworth (Universidad Complutense de Madrid, Spain) to present a lecture on an aspect of mycology of his choosing. It developed into, "Why don't we make it a full day meeting, and invite some more international speakers?" Steve Peterson (USDA, Peoria, USA), Jens Frisvad (BioCentrum-DTU, Lyngby, Denmark), and Rob Samson

(CBS, Utrecht, The Netherlands) were enlisted to give keynote lectures. In addition, David Hawksworth suggested that the most suitable papers be published in Revista Iberoamericana de Micología. The other speakers for the six open talks fell naturally into place and 11 posters completed the picture. We had 35 participants from ten different countries. A book of abstracts was produced and a few are still available upon request.

David Hawksworth's contribution focussed on the revolution that nucleic acid analysis is playing with respect to the systematics of fungi. There is at least the blessing of hope from the many potential curses (cf. Pandora's box), which must be to bring a more scientific approach to systematic mycology. This is placing taxonomy, if not centre stage, then significantly raising the profile within mycology as a whole. Furthermore, his estimation of 1.5 million species may be accounted for in part by the existence cryptic species. These are morphologically similar taxa which differ genetically. Although when the genetic differences are highlighted it is surprising how morphological differences subsequently can be found. In reality, it is not "morphology vs. molecular" but "molecular and morphology". However, why the use of nucleic acids in fungal systematics still is debated is difficult to explain when it is accepted in other organisms.

Multi-loci sequence analyses of nucleic acids in Penicillium and Eupenicillium was the field that Steve Peterson so ably presented. The impact has been immense in Penicillium. These advances promise to stabilize the taxonomy and improve concepts of evolution in critically important aspects of phytopathology and mycotoxicology. For example, Genetic Concordance Phylogenetic Species Recognition (GCPSR) was applied to Penicillium brevicompactum and some closely related species. When data from the three loci are plotted as layers on a single diagram, one can quickly recognize the species boundaries (see Peterson in this issue). Branches are concordant, or in this case, "not discordant", from the most recent common ancestor up to the tip area of the tree. The branching order of the three species is not specified in this tree because the data lack statistical support for which two of the three species are siblings. The patterns of descent based on each of the three loci are discordant in the tree tip areas. This very strongly implies that genetic rearrangements are occurring, or have occurred in the recent past. The GCPSR interpretation of the data is that they are isolates of a single species which can be deduced when isolates share the same gene pool, as the isolates in each of these three species appear to be doing. In addition, multilocus studies are obviously much more useful than single in that a more representative analysis is obtained. Incidentally, Steve confirms that the evidence of recombination events in anamorphs may be from parasexuality.

In a sense, Rob Samson and Jens Frisvad presented a joint paper supporting their recent publication on taxonomic schemes in subgenus Penicillium. This had the benefit of demonstrating the multi-disciplinary nature of their work. However, it appears now that even more penicillia have to find a place in a holomorph home. An alternative to the nucleic acids perspective was presented by Jens which again supported the role that extrolites (not just secondary metabolites) play. Dendrograms have now been produced of the data. Jens' term "extrolite" for those compounds (which include secondary metabolites) is interesting. It is a term for any metabolite that is expressed "outward" and is derived from the Jungian psychological concept of the extrovert. It is not to do with externally produced metabolites (i.e. extrolites not extralites).

Controversially, this could include compounds such as ergosterol and citric acid if it is overproduced. Rob Samson discussed polyphasic taxonomy in relation to the applied aspects of mycology: After all, the economic contribution of fungi is huge. It was gratifying that he had supervised proficiency testing in fungal identifications although the levels obtained were by no means $100 \%$ accurate. The results of his recent phenotypic study were expanded upon. Unfortunately, a manuscript is not available form their work for publication herein. 
Marc Stapler (Bayer HealthCare, Wuppertal, Germany) implied that the use of secondary metabolites to evaluate biodiversity in general is of considerable utility, with reference to the situation in the Hypoxyloideae (Xylariaceae). Over 2,000 specimens were employed in the study using HPLC methodology. Relationships based on the biogenesis of the pigments agreed reasonably with DNA analysis. In addition, some of these compounds were of relevance to natural products discovery. The extent of this work is impressive building as it does on the concepts of Whalley. The link between secondary metabolite taxonomy and natural product discovery requires to be fully recognised. Zofia Kozakiewicz (CABI Bioscience, Egham, UK) presented a paper on behalf of a consortium which included Micoteca da Universidade do Minho, on fungi isolated from a bottled water factory. Bottled water is increasingly being reported as having problems with fungal contamination. Her presentation concentrated on $P$. brevicompactum which was one of the predominant fungi isolated over the plant. Variation in the strains by "ERIC" molecular biology techniques indicating that a variety of different taxa may be present. Although some others appeared to be endemic to the factory. A very interesting talk on the mycoflora of cork bark used for wine corks was provided by Maria Basílio (Universidade Nova de Lisboa, Lisbon, Portugal). It is a unique and interesting process and one of huge significance to the Portuguese economy. The work was relevant particularly to "cork taint". The most dominant fungus appeared to be Chrysonillia sitophila and there was a high diversity of penicillia. The most frequent Penicillium was Penicillium glabrum and from DNA fingerprinting there appeared to be some geographical similarity between strains isolated from cork from regions of Portugal which may be useful information in the context of contamination control. Rita Serra (Universidade do Minho, Braga, Portugal) reported her work on fungi from Portuguese vineyards, with particular emphasis on ochratoxin A producing fungi from grapes. The extent of her data can only be admired. Interestingly, the grapes can be classified into the regions of origin based on the mycoflora detected. The practical use of the system may be in predicting regions of risk. Joëlle Dupont (Départment Systématique and Evolution, Paris, France) used RFLP of rDNA as a diagnostic tool for Biverticillium which made an interesting counterpoint to our own presentation of Paterson et al. The five restriction enzymes could discriminate between the 12 species investigated. However, Penicillium funiculosum was difficult to separate from Penicillium miniolutum, Penicillium pinophilum and Penicillium purpurogenum. It was noticeable that she confirmed a fairly high number of misidentified strains by other workers. Paterson et al.'s presentation focussed on an objective method for identifying fungi using minimal microscopy and appropriate analytical methods for mycotoxins. If species names for anamorphic fungi are no longer used then a scheme such as this may be appropriate, in addition to any merit it may already have at the applied level.

Finally, there were 11 poster presentations ranging from (a) the effects of plant extracts on stored product fungi, (b) synthetic compounds to inhibit mycotoxin production, and (c) the identification of fungi in schools. Underlying the international nature of the meeting, the Czech Republic was represented in this respect by Čeněk Novotý (Academy of Sciences of the Czech Republic) with a poster on the use of basidiomycetes for testing the toxicity of pollutants.

In conclusion, without doubt a most productive occasion which "worked" at a number of levels, and we hope was enjoyed by all those who attended. The primary theme was systematics which was supported by applied work. It would seem that molecular biology will continue to dominate the systematic debate, and it will be fascinating to observe how the other approaches support these schemes. Finally, secondary metabolites are useful not only as taxonomic characters but as natural products which are of interest in their own right. 